\title{
Scientometric analysis of the knowledge domain in nanotoxicology
}

\author{
Vladimir V. Chrishtop,* Artur Y. Prilepskii**, Varvara G. Nikonorova, Vladimir A. Mironov \\ International Institute "Solution Chemistry of Advanced Materials and Technologies" (SCAMT), \\ ITMO University, 9, Lomonosova str., Saint Petersburg, 191002, Russian Federation \\ * E-mail: chrishtop@ @camt-itmo.ru \\ **E-mail: prilepskii@ scamt-itmo.ru
}

The successful development and especially the commercialization and clinical translation of nanotechnology are unthinkable without nanotoxicology. Nanotoxicology in the last ten years has become an essential branch of knowledge, emerging at the intersection of nanotechnology and toxicology. However, despite its importance, the previous scientometric analysis of nanotoxicology was carried out ten years ago and is clearly outdated. The task was to scientometrically study the domain of nanotoxicology over the past decade. More than 3000 articles and 56 journals connected with nanotoxicology were analyzed. Two different nanotoxicology domains were established. The first one is associated with green synthesis and ecotoxicology. This approach formed a separate nanotoxicology branch, primarily presented in India, Iran, Saudi Arabia, and their close geographic partners. The constant search for biocompatible nanoparticles performing various functions in the body has become the focus of the USA, China, and some European countries. Cluster analysis also showed that there are two different approaches to nanotoxicology. Extensive growth of published articles relates to some of Asia's countries (India, Saudi Arabia, Iran), while intensive development is revealed for the USA, China, and Brazil. Analysis of new keywords showed possible trends in nanotoxicology for the near feature. Such keywords as biocompatibility, ecotoxicology, green synthesis, graphene oxide, and peptides can set future development directions.

\section{Introduction}

Since the 1970s, several toxicological and epidemiological studies have been conducted to assess the respiratory toxicity and pulmonary effects of "ultrafine" $(<100 \mathrm{~nm})$ particles versus larger particles (Churg \& Brauer, 2000; Ferin et al., 1990; G. Oberdörster, Ferin, Finkelstein, Wade, \& Corson, 1990; G Oberdörster, Ferin, Gelein, Soderholm, \& Finkelstein, 1992; Wilson, Hiller, Wilson, \& Bone, 1985). These studies anticipated the advent of nanotoxicology. However, the birth of nanotoxicology can be considered at $2000^{\text {th }}$ (Lison, Vietti, \& van den Brule, 2014). Several groups recommended frameworks and screening strategies for developing nanomaterials (NMs) that may be used safely, including the International Life Sciences Institute (ILSI), the European Centre for Ecotoxicology and Toxicology of Chemicals (ECETOC), and a collaborative partnership between DuPont Corporation and Environmental Defense (Krabbenborg, 2013; Günter Oberdörster, Maynard, et al., 2005; Warheit, Webb, Reed, Frerichs, \& Sayes, 2007).

In 2005, the International Life Sciences Institute Research Foundation/Risk Science Institute assembled a working group of experts to assess NMs toxicological knowledge's current state and formulate guidelines for this newfound field's progression. This working group established the original screening mission for 'hazard identification' following NMs exposure (Hussain et al., 2015). A bright future was predicted for the nanomaterial industry at this stage, but the risks associated with nanotoxicology were underestimated (Service, 2008). Lux Research estimated the market for pure nanomaterials (carbon nanotubes, nanoparticles, quantum dots, dendrimers, etc.) to grow to approximately $\$ 3.6$ billion by 2010 (from $\$ 413$ million in 2005), and they forecasted the entire "nanotechnology impact" by 2010 to be approximately $\$ 1500$ billion (Nano-Society, 2009). In 2010, the General Accounting Office (GAO) predicted that the global market for nanotechnology-related 
products would grow and, by 2015 , will amount to between $\$ 1-2.6$ trillion (United States Government Accountability Office, 2010). However, in 2019 the global nanomaterials market size was valued at $\$ 8.5$ billion and is expected to grow at a compound annual growth rate (CAGR) of only $+13.1 \%$ from 2020 to 2027 (Inshakova \& Inshakov, 2017). There is still a lack of a big-scale "nano" manufacturing industry associated with producing NMs. Also, many risky materials are getting integrated into products, which do not have the potential for release yet (Singh et al., 2019).

Thus, 2010 - 2011 became the borderline where the formation of the concept of nanotoxicology was formulated. The UK launched a voluntary reporting scheme for nanomaterials in 2008 that targeted manufacturers, importers, and users (Department for Environment Food and Rural Affairs, 2008). However, after $1-2$ years, such requirements from the USA, EU, Australia, and Canada authorities have become mandatory (Santamaria, 2012). This was facilitated by the understanding that not all concepts in chemical safety can be readily translated into nano-sized objects (Stark, 2011).

The subsequent development of nanotoxicology consisted of the development of nanotechnology and the requirements to assess the toxicity of new NMs, and the integration of nanotoxicology into nearby scientific fields. One of the most important aspects was the formation of protein corona (Neagu et al., 2017) and nanotoxicity prediction (Furxhi, Murphy, Mullins, \& Poland, 2019). Additionally, advanced animal models need to be developed for nanotoxicological research (Fadeel, 2019).

The term nanotoxicology has seriously changed over time.

2004: particle toxicology is a mature science that has addressed lung injury mechanisms caused by nanoparticles. The term ultrafine particles have been used to denote nanoparticles (Donaldson, Stone, Tran, Kreyling, \& Borm, 2004).

2005: nanotoxicology is an emerging discipline that can be defined as the "science of engineered nanodevices and nanostructures that deals with their effects in living organisms" (Günter Oberdörster, Oberdörster, \& Oberdörster, 2005).

2010: "nanotechnology, nanomedicine, and nanotoxicology are complementary disciplines aimed at improving human life. Nanotechnology has a bright future with multiple applications in engineering, optics, energy, consumer products. Nanomedicine will develop applications for novel and superior diagnostic, therapeutic, and preventive measures. Nanotoxicity provides for the necessary safety assessment of nano-enabled products" (G. Oberdörster, 2010). At this stage, the formation of the central concept of nanotoxicology is finished.

2019: nanotoxicology is a subfield of toxicology concerned with the potentially toxic effects of nanoscale structures or particles with a diameter of less than $100 \mathrm{~nm}$ (Singh et al., 2019).

2019: nanotoxicology is a branch of toxicology that analyses the toxicity of NPs (Furxhi et al., 2019).

However, even today, researchers remain dissatisfied with the sufficiency of nanotoxicology's terminological and methodological apparatus. Nanotechnology is an emerging, cross-disciplinary technology designed to create and synthesize new materials at the nanoscale (generally defined as a particle with a size of $1-100 \mathrm{~nm}$ ) to generate innovative or altered material properties (Warheit, 2018). Despite numerous potential biomedical applications, engineered nanomaterials' toxicological perspective is poorly understood or somewhat unclear, gaining considerable attention in nanotoxicology. However, nanotoxicology is in the embryonic stage of its development. It is a vital part of nanomedicine and discusses interactions of engineered nanomaterials with biological systems or environments. Emphasis is given to the correlations between nanomaterials' physicochemical and surface properties by inducing toxic or adversarial biological responses (Navya \& Daima, 2016). In this regard, it seems essential to study nanotoxicology development in 2010 - 2011 to predict its development trends. Scientometrics is an important tool for this task. Scientometrics is a branch of informatics that analyzes patterns in the scientific literature, intending to comprehend emerging trends and a research area's knowledge structure (de Castilhos Ghisi, Zuanazzi, Fabrin, \& Oliveira, 2020). It 
has been successfully applied many times to analyze the state of nanotechnology (Anandhalli, 2018; Karpagam, 2014; Takeda, Mae, Kajikawa, \& Matsushima, 2009) nanopharmaceutics (Yeung et al., 2020), and nanotoxicology. However, they do not cover the post-2014 period.

The objective of the current review is to identify ten years research trend in nanotoxicology with the aim to 1) study global research trends related to nanotoxicology; 2) identify contribution and citation impact of top journals related to nanotoxicology; 3) identify contribution and citation impact of top articles and edited books related to nanotoxicology; 4) identify the contribution of top scientists; 5) identify contribution and citation impact of most productive countries related to nanobiotechnology and group up international collaborations; 6) identify the contribution of top 10 institutions; 7) identify and characterize the combinations of keywords related to nanotoxicology for 2015-2020.

\section{Materials and methods}

\subsection{Data search and processing}

The data was obtained from the Dimensions database. The search terms for the data were set as: (nanotechnology toxicity). The search was performed on titles and abstracts. 3994 results were obtained, further refined by year category (from 2011 to July 2020), resulting in 3311 results. Obtained ten-year data (2011-2020) was analyzed through the parameters of document types, publication output, country output, most productive authors, most productive journals, etc.

We created a sample of journals with at least ten publications in the study area from 2011 to 2020 to study the citation indicators and scientific journals' contributions. The sample consisted of 56 journals. Subsequently, the journals were ranked according to the number of articles, the total number of citations, and the mean value of citations.

To identify and research the top scientists in nanotoxicology, we created a sample of personalities with at least five publications in the study area from 2011 to 2020. The sample consisted of 67 scientists. Ranking proceeded in the same manner as for journals.

Finally, we performed cluster analysis of countries, organizations, and journals based on coauthorship and citation data. The analysis was based on a database search terms "nanotechnology toxicity (Search in: Full data)". 2312 publications were obtained as the data for cluster analysis for the 2015-2020 years. Validated data were choosing the Save/Export option, followed by the Export for bibliometric mapping option.

The PubMed database was used to study the combination of keywords. The search terms for the data were set as "nanotechnology toxicity [Title/Abstract]". The data for articles from 2015 to 2020 was exported. The 2015 database included 621 articles, 2016 - 621 articles, 2017 - 693 articles, 2018 - 703 articles, 2019 - 743 articles, and 2020 - 793 articles. Cluster analysis was carried out to determine the dynamics of keywords for each database: type of analysis - co-occurrence, unite of analysis - all keywords. Minimum numbers of keyword occurrences were selected so that the final number of keywords included in the analysis did not exceed 100. For analysis of co-occurrence of keywords firstly used in 2020, to identify future trends, we analyzed the database of articles for 2020 with minimum numbers of occurrences of a keyword $=2$. The number of keywords included in this graph was 674 .

\subsection{Scientometric analysis method}

VOSviewer software (version 1.6.16, released on November 25, 2020) was used for bibliometric analysis and to plot bibliometric networks (van Eck \& Waltman, 2010). The terms were organized into clusters, with each cluster represented by a color. More important terms had larger circles than less important ones, and strongly related terms were positioned closer. Moreover, lines were drawn between items to indicate relations, with thicker lines indicating a stronger link between 2 items (van Eck \& Waltman, 2010; van Eck, Waltman, van Raan, Klautz, \& Peul, 2013). Because VOSviewer software cannot identify singular and plural nouns, or different spellings of the same keyword, such 
keywords were excluded when plotting keyword co-occurrence graphs. Thus, for 2015, 99 keywords were analyzed, for 2016 - 98, for 2017 - 96, for 2018 - 95, for 2019 - 96, for 2020 - 96 keywords.

\section{Results and discussion}

\subsection{Study of global research trend in the field of nanotoxicology}

Data were obtained from the Dimensions database because it has one of the broadest scientific literature coverage. By December 2019, the Dimensions database contained more than 106 million publications - around 30\% more than comparable databases. It now has more than 106 million publications, with over 1.2 billion citations openly accessible at app.dimensons.ai.

Table 1 shows the growth of publications published in the Dimensions database from 2001 to 2020. Altogether there are 3316 publications published. The highest number of articles (578) was contributed in 2020, representing $+17.43 \%$ of the reviewed articles. The least number of articles were published in the year $2011-213$ articles $(+6.42 \%)$. The average annual increase in the number of articles was $+12.37 \%$. The minimum growth was recorded in 2013, 2015, 2016, and $2018(+0.4 \%,-1.39 \%$, $+4.58 \%$, and $-1.37 \%$, respectively). In the last two years, there has been an increase in publications $+18.66 \%$ in 2019 and $+35.68 \%$ in 2020 . The total number of citations of analyzed publications in the Dimensions database from 2001 to 2020 was 97813. The average annual increase in the number of citations was $+97.11 \%$. The minimum growth was recorded in $2018(+6.63 \%)$. The last two years have increased the number of citations by $+29.18 \%$ in 2019 and $+32.71 \%$ in 2020 .

Table 1. Global research trend related to nanotoxicology

\begin{tabular}{|c|c|c|c|c|c|c|c|c|c|c|}
\hline Year & 2011 & 2012 & 2013 & 2014 & 2015 & 2016 & 2017 & 2018 & 2019 & 2020 \\
\hline Publications (total) & 213 & 253 & 254 & 288 & 284 & 297 & 364 & 359 & 426 & 578 \\
\hline Citations (total)* & 237 & 1419 & 3576 & 5793 & 8078 & $\begin{array}{c}1044 \\
4\end{array}$ & $\begin{array}{c}1295 \\
0\end{array}$ & $\begin{array}{c}1380 \\
8\end{array}$ & $\begin{array}{c}1783 \\
7\end{array}$ & $\begin{array}{c}2367 \\
1\end{array}$ \\
\hline $\begin{array}{c}\text { Publications with } \\
\text { citations (\%, } \\
\text { citation) }\end{array}$ & $\begin{array}{c}91.5 \\
5\end{array}$ & $\begin{array}{c}94.4 \\
7\end{array}$ & $\begin{array}{c}93.3 \\
1\end{array}$ & $\begin{array}{c}94.4 \\
4\end{array}$ & $\begin{array}{c}94.3 \\
7\end{array}$ & $\begin{array}{c}93.6 \\
0\end{array}$ & $\begin{array}{c}91.2 \\
1\end{array}$ & $\begin{array}{c}86.6 \\
3\end{array}$ & $\begin{array}{c}80.5 \\
6\end{array}$ & $\begin{array}{c}39.7 \\
9\end{array}$ \\
\hline RCR (mean)** & 2.57 & 2.76 & 2.22 & 2.27 & 1.73 & 1.9 & 2.17 & 2.23 & 0 & 0 \\
\hline
\end{tabular}

* Publication citations are the number of times that other publications in the database have cited publications.

** The Relative Citation Ratio (RCR) indicates the relative citation performance of a publication when comparing its citation rate to other publications in its area of research.

The Relative Citation Ratio of the investigated group of publications in 2011, which was 2.57, decreased until 2015 (to 1.73), but after that, it constantly increased, reaching 2.23 by 2018. The Relative Citation Ratio (RCR) is a new metric recently endorsed by the National Institutes of Health. It is based on weighting the number of citations a paper receives to a comparison group within the same field (Hutchins, Yuan, Anderson, \& Santangelo, 2016). The research area is defined by the corpus of publications co-cited with the article of interest (the "co-citation network") - it is therefore dynamically defined. In other words, the RCR indicates how a publication has been cited relative to other publications in its co-citation network, and this is assumed to be reflective of the article's area of research. The key aspect of the derivation of the RCR is that it is benchmarked to NIH R01-funded articles. If the article's RCR value is 1.0 - the article is in the median for NIH R01-funded articles for that year. This definition leads to a clear interpretation of RCR values: RCR value of 1.0 is the boundary between articles with a citation rate lower than the median NIH R01-funded publication and 
those with a higher citation rate (Surkis \& Read, 2015). Thus, the annual increase in the number of publications and citations indicates the great importance of nanotoxicological research in the general field of research on nanobiotechnology.

\subsection{The contribution and citation impact of top journals related to nanotoxicology}

Nanotoxicology exists at the cross of medicine, toxicology, and nanotechnology (G. Oberdörster, 2010). From this perspective, we consider the division of journals related to nanotoxicology into three clusters presented in Figure 1.

In our opinion, the journals of the "red" cluster can be considered as journals focusing on chemistry. The green cluster journals can be considered as journals focusing on toxicology. Blue cluster journals can be considered primarily as journals focusing on medicine and biology.

In our opinion, the division of journals citation into three branches reflects the definition of nanotoxicology given in 2010 by Oberdörster and demonstrates the absence of specialized journals focusing on nanotoxicology as an interdisciplinary field of knowledge. The appearance of such a journal would contribute to the development of conceptual and methodological apparatus of nanotoxicology. Table 2 shows that the top nanotoxicology journals. These journals are characterized by many articles on nanotoxicology published from 2011 to 2020 and their high citation rate.

3.3.The contribution and citation impact of top articles and edited books related to nanotoxicology

Books make a significant contribution to the systematization and development of the methodological and conceptual apparatus of science. Below we demonstrate that nanotoxicology's most popular books and articles are related to the ecological, medical, and cytological approaches in the nanotoxicological methods (Table S1, S2).

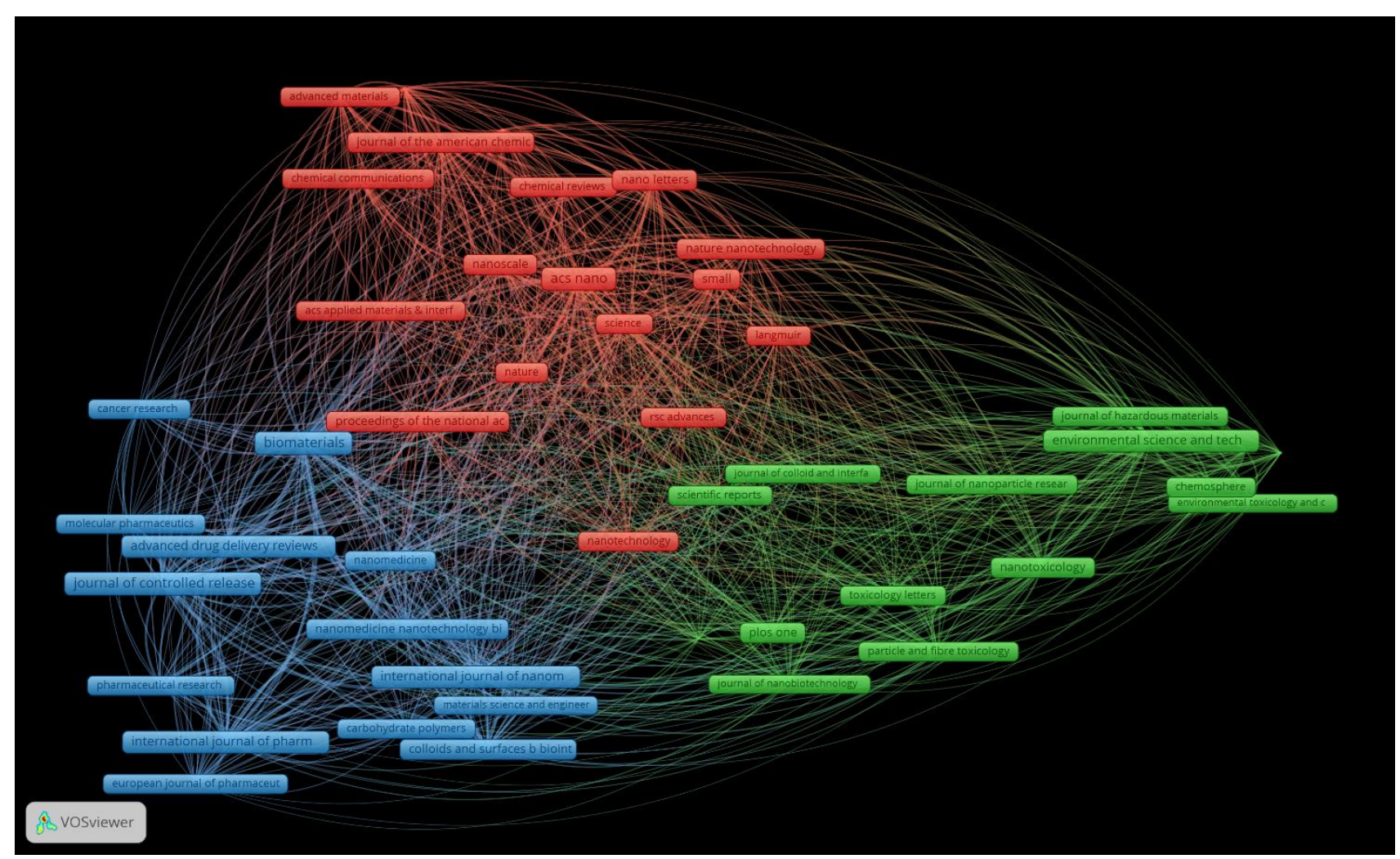

Figure 1. Journals co-citation clusters. The figure demonstrates three main clusters of journals co-citing, consisting of 48 journals with at least 700 citation links. The journals of the "red" cluster are mainly focused on chemistry, while the "blue" cluster is focused on medicine and biology, and the "green" cluster is focused on toxicology 
Table 2. Most productive journals in the field of nanotoxicology

\begin{tabular}{|c|c|c|c|c|c|c|c|c|c|c|c|}
\hline \multicolumn{4}{|c|}{$\begin{array}{l}\text { Journals with the highest number of } \\
\text { publications in the field of study }\end{array}$} & \multicolumn{4}{|c|}{ Journals with the most citations } & \multicolumn{4}{|c|}{$\begin{array}{l}\text { Journals with the highest citations } \\
\text { (mean) }\end{array}$} \\
\hline $\mathrm{N}^{*}$ & $\mathbf{P}^{*}$ & $\mathrm{C}_{\mathrm{i}}^{*}$ & $\mathrm{C}_{\mathrm{im}} *$ & $\mathrm{~N}^{*}$ & $\mathrm{P}^{*}$ & $\mathbf{C}_{\mathrm{i}}^{*}$ & $\mathrm{C}_{\mathrm{im}} *$ & $\mathrm{~N}^{*}$ & $\mathrm{P}^{*}$ & $\mathrm{C}_{\mathrm{i}}^{*}$ & $\mathrm{Cim}_{\mathrm{im}} *$ \\
\hline $\begin{array}{c}\text { International } \\
\text { Journal of } \\
\text { Nanomedicin } \\
\text { e }\end{array}$ & 67 & 2594 & 38.72 & ACS Nano & 46 & 4433 & 96.37 & $\begin{array}{l}\text { Accounts } \\
\text { of } \\
\text { Chemical } \\
\text { Research }\end{array}$ & 11 & 2365 & 215 \\
\hline ACS Nano & 46 & 4433 & 96.37 & $\begin{array}{c}\text { Journal of } \\
\text { Controlled } \\
\text { Release }\end{array}$ & 35 & 2643 & 75.51 & $\begin{array}{l}\text { Particle and } \\
\text { Fibre } \\
\text { Toxicology }\end{array}$ & 12 & 1181 & 98.42 \\
\hline $\begin{array}{c}\text { International } \\
\text { Journal of } \\
\text { Pharmaceutics }\end{array}$ & 40 & 1148 & 28.70 & $\begin{array}{c}\text { International } \\
\text { Journal of } \\
\text { Nanomedicine }\end{array}$ & 67 & 2594 & 38.72 & ACS Nano & 46 & 4433 & 96.37 \\
\hline Nanoscale & 39 & 1528 & 39.18 & $\begin{array}{c}\text { Accounts of } \\
\text { Chemical } \\
\text { Research }\end{array}$ & 11 & 2365 & 215 & $\begin{array}{l}\text { Advanced } \\
\text { Drug } \\
\text { Delivery } \\
\text { Reviews }\end{array}$ & 14 & 1115 & 79.64 \\
\hline $\begin{array}{c}\text { Journal of } \\
\text { Controlled } \\
\text { Release }\end{array}$ & 35 & 2643 & 75.51 & Nanoscale & 39 & 1528 & 39.18 & $\begin{array}{c}\text { Journal of } \\
\text { Controlled } \\
\text { Release }\end{array}$ & 35 & 2643 & 75.51 \\
\hline $\begin{array}{c}\text { Current } \\
\text { Pharmaceutic } \\
\text { al Design }\end{array}$ & 33 & 545 & 16.52 & Small & 23 & 1379 & 59.96 & $\begin{array}{c}\text { Environme } \\
\text { ntal } \\
\text { Science } \\
\text { and } \\
\text { Technolog } \\
\text { y }\end{array}$ & 17 & 1168 & 68.71 \\
\hline Nanomedicine & 29 & 1041 & 35.9 & Biomaterials & 24 & 1342 & 55.92 & $\begin{array}{c}\text { Journal of } \\
\text { Nanobiotec } \\
\text { hnology }\end{array}$ & 15 & 1010 & 67.33 \\
\hline $\begin{array}{c}\text { Expert } \\
\text { Opinion on } \\
\text { Drug Delivery }\end{array}$ & 28 & 857 & 30.61 & $\begin{array}{l}\text { The Science of } \\
\text { The Total } \\
\text { Environment }\end{array}$ & 26 & 1327 & 51.04 & PLoS ONE & 19 & 1185 & 62.37 \\
\hline Nanomaterials & 27 & 518 & 19.19 & PLoS ONE & 19 & 1185 & 62.37 & Small & 23 & 1379 & 59.96 \\
\hline $\begin{array}{l}\text { The Science } \\
\text { of The Total } \\
\text { Environment }\end{array}$ & 26 & 1327 & 51.04 & $\begin{array}{l}\text { Particle and } \\
\text { Fibre } \\
\text { Toxicology }\end{array}$ & 12 & 1181 & 98.42 & $\begin{array}{l}\text { Archives of } \\
\text { Toxicology }\end{array}$ & 13 & 771 & 59.31 \\
\hline $\begin{array}{c}\text { Journal of } \\
\text { Nanoscience } \\
\text { and } \\
\text { Nanotechnolo } \\
\text { gy } \\
\end{array}$ & 26 & 459 & 17.65 & $\begin{array}{c}\text { Environmental } \\
\text { Science and } \\
\text { Technology }\end{array}$ & 17 & 1168 & 68.71 & $\begin{array}{l}\text { Biomaterial } \\
\mathrm{s}\end{array}$ & 24 & 1342 & 55.92 \\
\hline $\begin{array}{l}\text { Nanotoxicolo } \\
\text { gy }\end{array}$ & 25 & 1131 & 45.24 & $\begin{array}{l}\text { International } \\
\text { Journal of } \\
\text { Pharmaceutics }\end{array}$ & 40 & 1148 & 27.70 & $\begin{array}{l}\text { Materials } \\
\text { Science } \\
\text { and } \\
\text { Engineerin } \\
\text { g C }\end{array}$ & 13 & 719 & 55.31 \\
\hline
\end{tabular}

$* \mathrm{~N}$ - name, $\mathrm{Ci}$ - number of citations, $\mathrm{Ci}_{\mathrm{m}}$ - mean number of citations.

\subsection{The contribution of top scientists in nanotoxicology}

It is essential to study the CVs of top nanotoxicologists (Table S3) to study the state of nanotoxicology as a field of scientific knowledge (in addition to assessing the conceptual and methodological apparatus).

Based on the assessment of the data in Table S3, the number of citations, the average number of citations per publication, and, to a lesser extent, the number of publications issued on the topic, we present Table S4 of the top-5 best nanotoxicologists for 2011 - 2020 according to the Dimensions database. Short biography of three researchers with the highest H-indices, according to Google Scholar, is presented in Supporting Information. 
Based on the study of the biographies of leading nanotoxicologists, in our opinion, there is a shortage of professional biological and medical specialists. However, leading scientists of the industry took part in the creation of textbooks and monographs on nanotoxicology. It allows us to hope for the appearance of an interdisciplinary (biological, chemical, medical, and environmental) complex of competencies in the next generations of specialists.

\subsection{The contribution and citation impact of most productive countries related to nanobiotechnology}

The condition for including countries in the analysis was at least 50 publications on nanotoxicology. The first cluster analysis was performed to identify groups of co-authorship (Figure 2). The analysis identified the top-14 countries distributed in three clusters. The "green" cluster included countries with the most cited scientists, as demonstrated in Table S3. These countries are the USA, China, UK, and Australia. The "blue" cluster was formed by Asia countries: India, Saudi Arabia, South Korea, due to the geographic proximity. The "red" cluster includes the remaining countries: Brazil, Canada, France, Germany, Iran, Italy, Spain.

Even more interesting was clustering analysis by citations (Figure 3). The "blue" cluster was represented by countries aimed at the ecotoxicological aspect of nanotoxicology and applied science connected with agriculture. France, Italy, Spain, and Brazil (the "green" cluster) have high science capabilities that split their effort on fundamental and applied investigations. The "red" cluster, in our opinion, is mainly dedicated to fundamental science and represented by world-leading countries.

Summarizing the data obtained for countries, we compiled the map (Figure 4) based on the cluster analysis data and the occurrence of countries evaluated in Tables S3, S4, and Figures 2, 3.

\subsection{Identify the contribution of top institutions}

Our next step was to determine the top universities contributing to nanotoxicology and analyze the co-authorship between institutions. The results are presented in Figure 5. The central "red" cluster, which has connections with all other groups of organizations (except for the "green" cluster), has been formed by Harvard University (USA), King Abdulaziz University (Saudi Arabia), Shanghai Jiao Tong University (China), and Zhejiang University (China).

The "green" cluster is the most isolated and is represented by King Saud University (Saudi Arabia), Amity University (India), and Aligarh Muslim University (India). It has links only with the "blue" cluster, which includes Jamia Hamdard (India), Panjab University (India), and International Medical University (Malaysia). The "purple" cluster is composed of Tehran University of Medical Sciences (Iran) and Tabriz University of Medical Sciences (Iran). The "yellow" cluster is formed by the National Center for Nanoscience and Technology (China) and the University of Chinese Academy of Sciences (China).

Clustering based on organizations co-authorship (Figure 5) demonstrates that Indian and Iran organizations are as far away (isolated) as possible from the center of world co-authorship at Harvard University. A clustering analysis carried out for countries (Figure 2) demonstrates similar results.

Such isolation can explain the very low citation rates of works by authors affiliated with Indian organizations even though they hold the leading position in terms of the total number of publications in the field of nanotoxicology (Table S3). In our opinion, this is evidenced in Figure 6. Most Indian and Iran organizations integrated into a cluster isolated from the cluster of American and Chinese organizations. In our opinion, it demonstrates that the research of the leading Indian organizations focused on their own country (applied aspects) or Saudi Arabia and Malaysia. Simultaneously, research of the USA, China, and, to a less extent, Saudi Arabia organizations have global, fundamental aspects. 


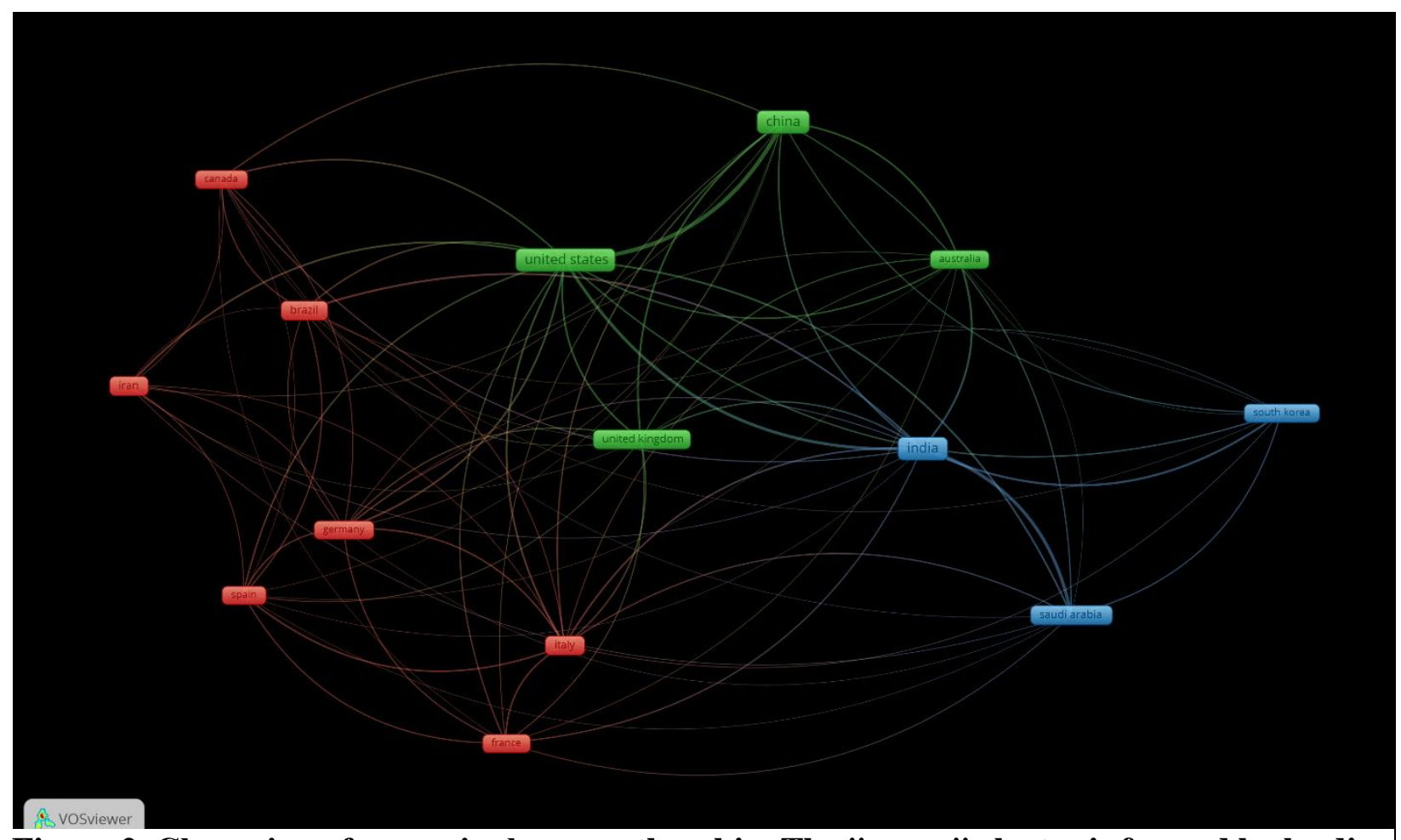

Figure 2. Clustering of countries by co-authorship. The "green" cluster is formed by leading countries gathering around the USA. The "blue" cluster is most isolated and represented by Asia's countries. The "red" cluster is formed from leading European countries (Germany, Spain, Italy, and France), which are closely connected, possibly due to joint foundation programs. However, the rest of the "red" cluster countries (Iran, Brazil, and Canada) also have numerous connections with the first four countries but lack connections between each other.

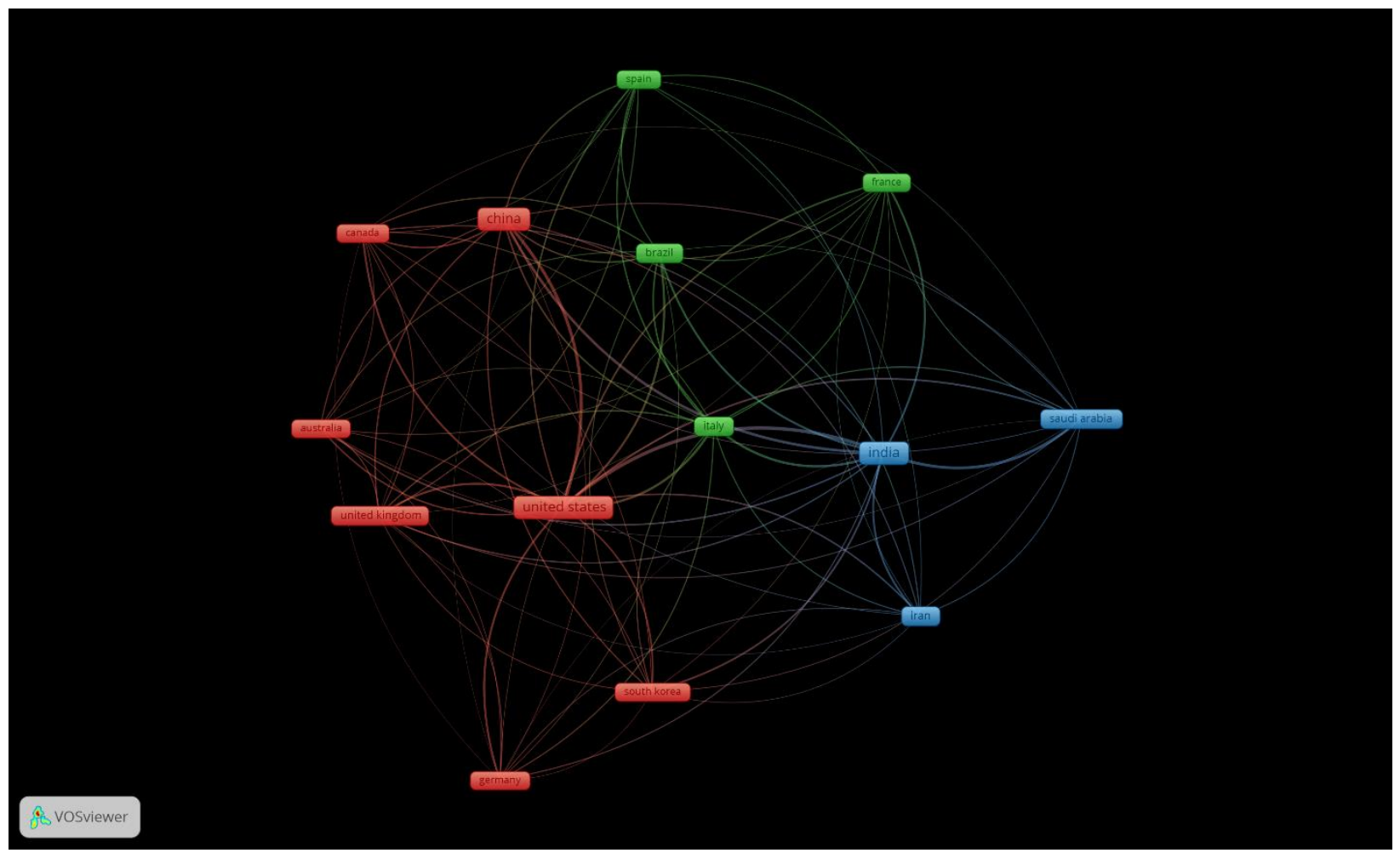

Figure 3. Clustering of countries by citation. USA, China, Great Britain, Canada, Australia, Germany, South Korea form a "red" cluster. The "green" cluster is formed by Latin and European countries and includes France, Italy, Spain, and Brazil. The "blue" citation cluster was formed by Asia's countries: India, Saudi Arabia, and Iran. 

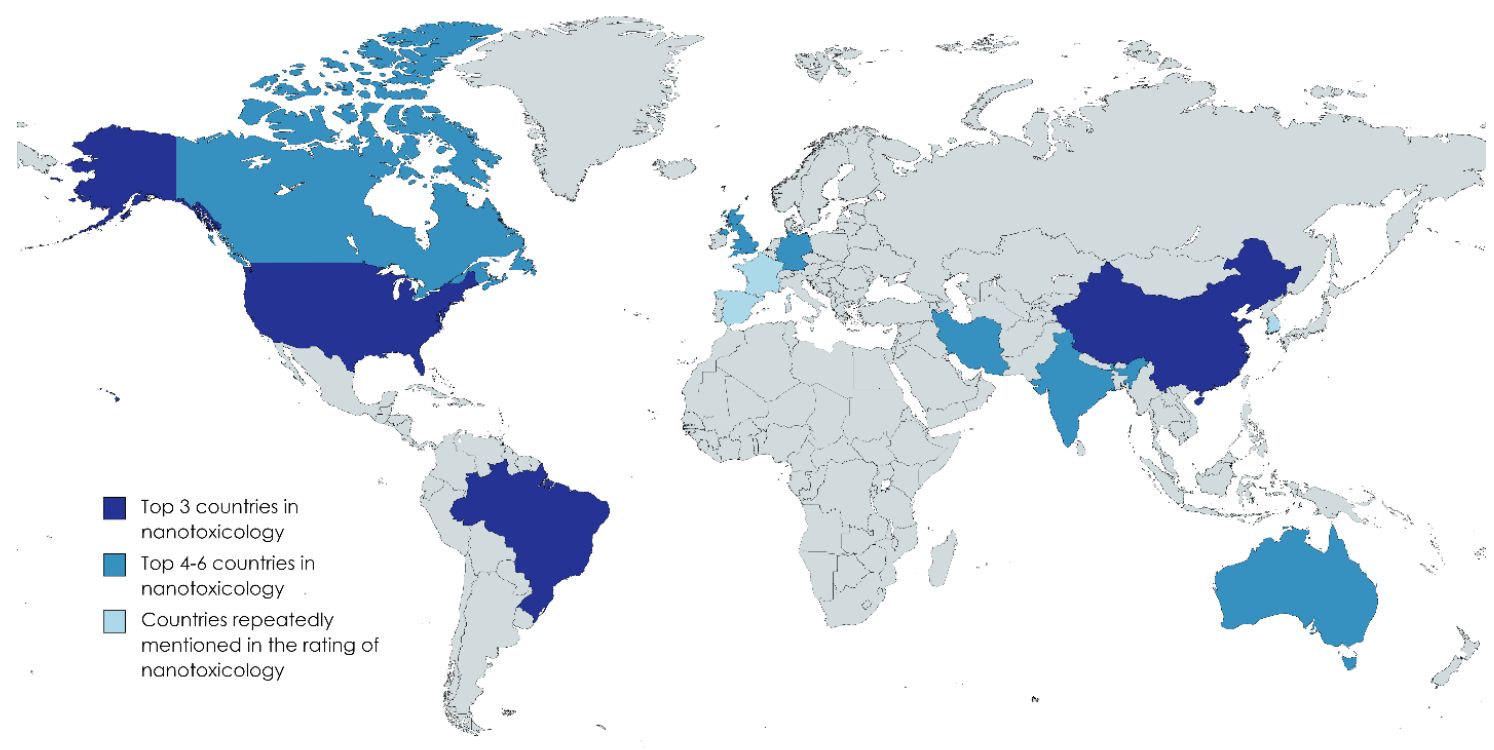

Figure 4. Map of the top-9 countries in nanotoxicology. The USA, China and Brazil made the most significant contribution. Countries mentioned earlier at least three times include UK, Australia, Canada, India, Iran, and Germany. The countries that appear twice in the above rankings include Spain, France, and South Korea.

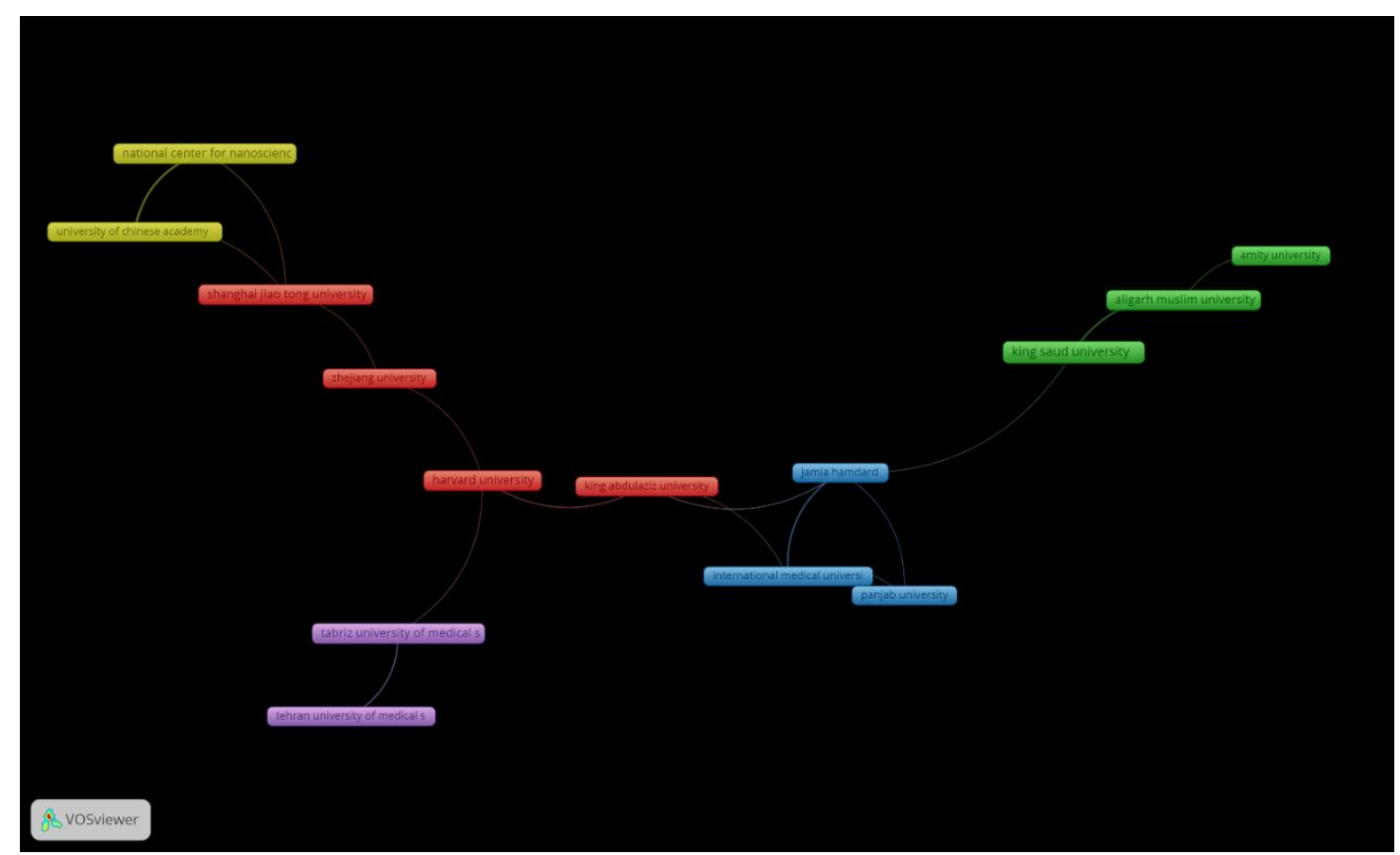

Figure 5. The clustering of organizations with at least 14 publications on nanotoxicology, based on the co-authorship of their researchers. Most of the clusters ("green", "yellow", "purple", and "blue") are grouped following geographic proximity. The "red" cluster is multinational, which is in our opinion, is beneficial for nanotoxicology development.

In Figure 6, "blue" and "green" clusters are most integrated into the general citation scheme. The "blue" co-citation cluster includes Harvard University (USA) and two Chinese universities - Shanghai Jiao Tong University and Zhejiang University. Interestingly, in Figure 5, both Chinese universities were separated in the "yellow" cluster. This fact shows potential interest in collaboration which was not yet established. Surprisingly, two Saudi Arabia universities (King Saud University and King Abdulaziz University) have neither collaborations (Figure 5) nor co-citations (Figure 6). In general, many universities that have co-authorships do not have co-citations. We can explain this by the fact 


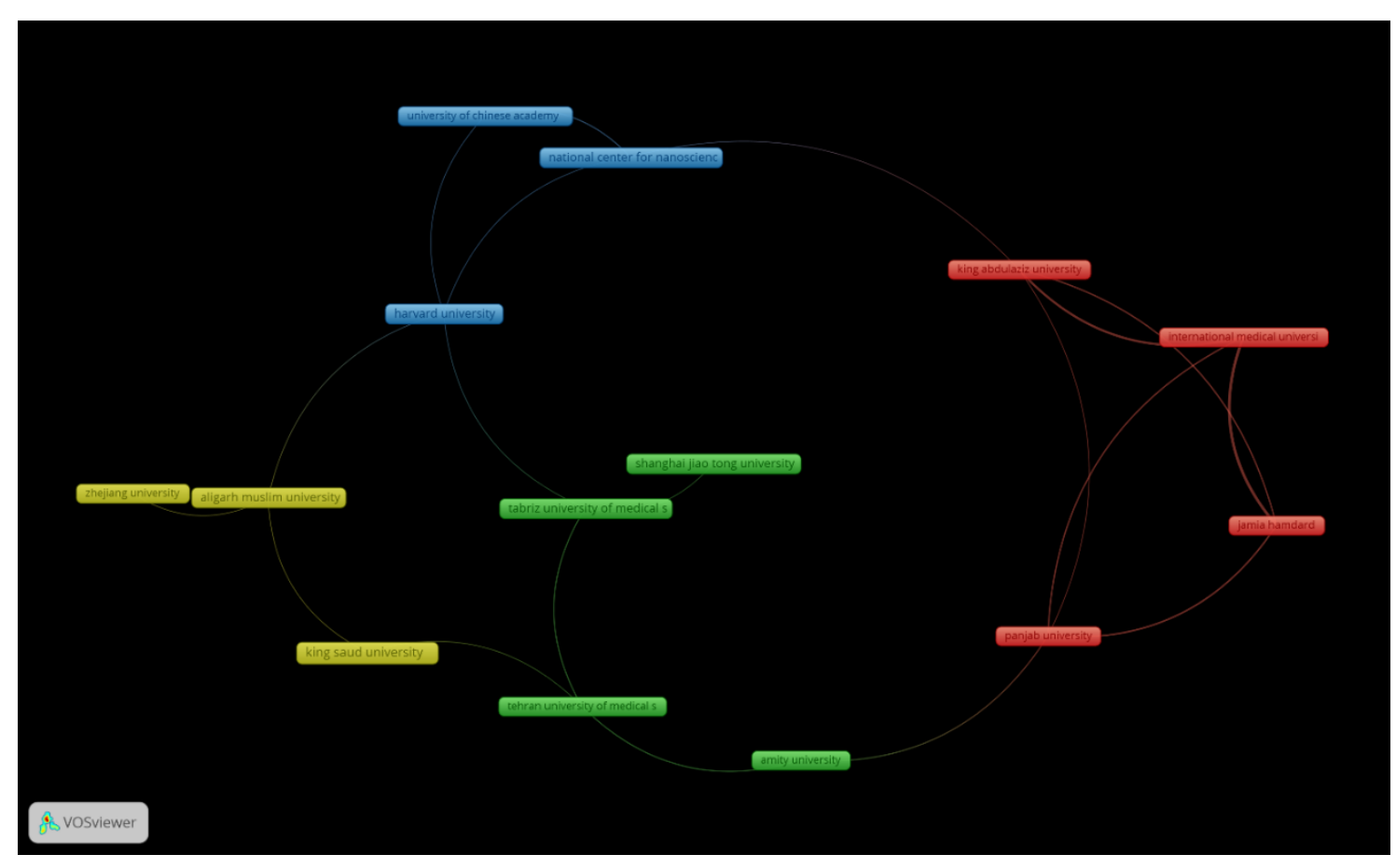

Figure 6. The clustering of organizations presented in Figure 5 based on their co-citations. Harvard University (USA) still act as the leading center for both fundamental and applied research. Some universities have connections based on co-authorships (Figure 5) but do not have links for co-citations. This may be because some co-authorships connections established in terms of mutual use of scientific equipment. At the same time, the research topics of these universities (or research groups) are different.

that many scientific groups help each other with scientific equipment, but at the same time, they are engaged in entirely different research topics.

\subsection{Analysis of the keyword combinations for 2015 - 2020}

A discipline's history can be traced from analyzing the evolution of relevant keywords retrieved from articles of mainstream scientific journals (Trevisani \& Tuzzi, 2018). The combination of keywords that remain unchanged can be considered as nanotoxicology conceptual core, reflecting the unchanging essence of science. We analyzed the main keywords and presented them in Table S5.

The definition of nanotoxicology as a discipline should include keywords identified throughout its existence, except for words related to the methodological apparatus. As a result, the list of most essential keywords can be narrowed to anti-bacterial agents, antineoplastic agents, biocompatible materials, cytotoxicity, response relationship, drug carriers, drug delivery, liposomes, nanoparticles, micelles, nanomedicine, nanoparticles, nanostructures, risk assessment, theranostic nanomedicine. Unexpectedly for us, theranostic nanomedicine has been associated with the search term for nanotoxicology over the past decade.

Based on the findings, we can propose an alternative nanotoxicology definition based on the identified keyword patterns. Nanotoxicology is an interdisciplinary branch of knowledge that studies the interaction of biomolecules, microorganisms, cells, organisms, and biogeocinosis with nanoparticle and nanofiber carriers, independent drugs, and theranostic agents in nanomedicine to reduce the risk of toxic outcomes.

Some of the keywords are encountered for the first time only in 2020. These keywords are antimicrobial, autophagy, biocompatibility, caco-2 cells, cadmium, cancer therapy, chemotherapy, cisplatin, daphnia, ecotoxicity, ecotoxicology, graphene oxide, green synthesis, hyaluronic acid, 
nanotoxicity, nanotoxicology, peptides. We decided to focus our attention on some of these words as potential trends. We determined their relationships with other keywords in 2020 (Figure 7).

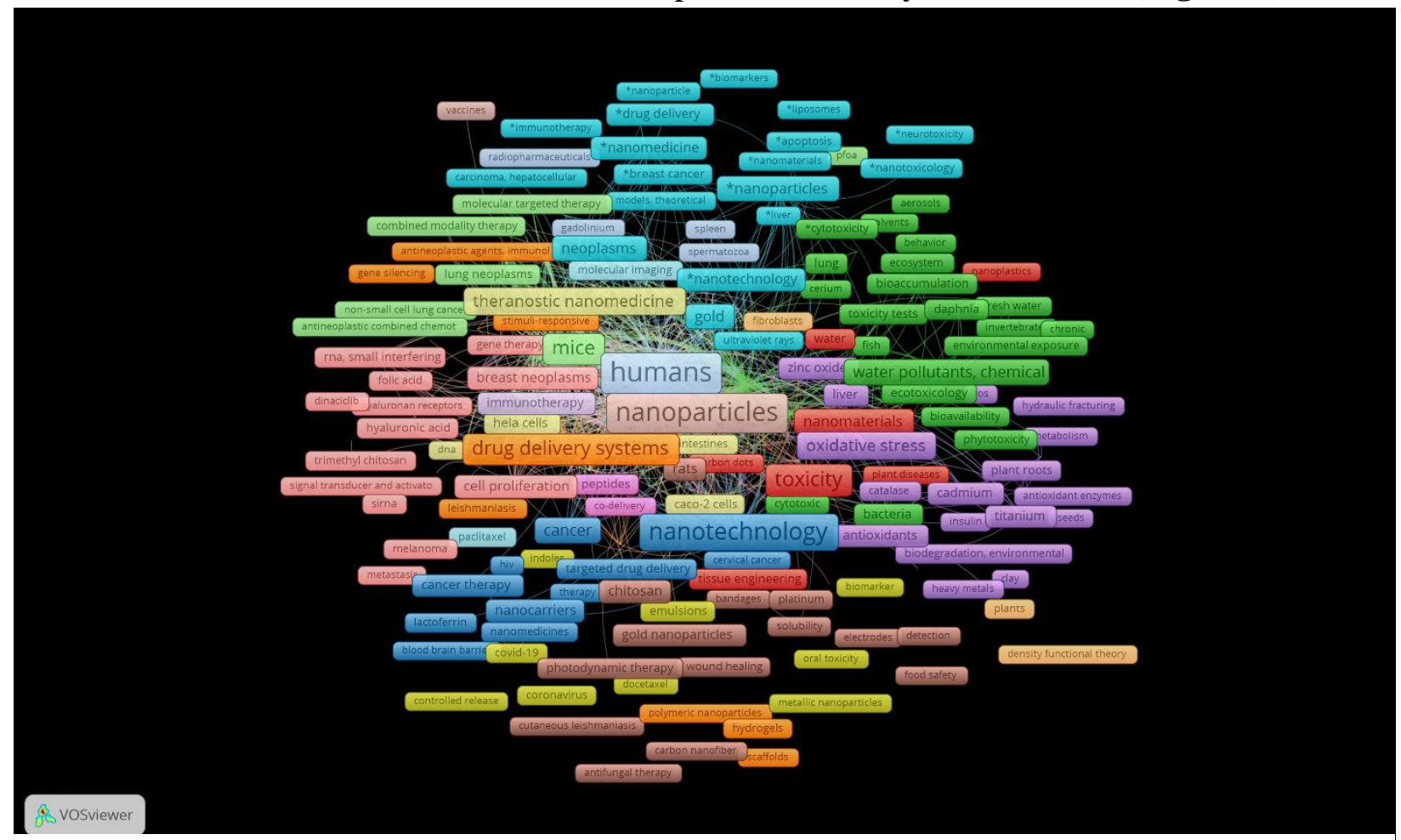

Figure 7. Main keywords in 2020 and their co-occurrence. The "green" cluster is associated with environmental pollutants (e.g., cadmium) and ecotoxicology. The "purple" cluster is associated with heavy metals and oxidative stress. The "brown" cluster is associated with noble metals and medical application. The "blue" cluster is associated with targeted delivery and cancer treatment. The "pink" cluster is associated with nanoparticles functionalization strategies. The "light blue" cluster is associated with biodistributions, nanotoxicity, and nanomedicine.

Figure 7 shows keyword relationships in 2020. While some of the keyword clusters are clearly distinguished, there are also some keywords on the crossings. Based on Figure 7, we compiled Table S6 showing the relations between new keywords. We included in the analysis only those keywords that form links with the keywords first identified in 2020.

Thus, Table S6 shows two main directions of nanotoxicology development. The first is formed by $1,2,3,5$, and 10 lines and is represented by countries like the USA and China. It is associated with the more active inclusion of various peptides into the composition of nanoparticles, both to target nanoparticles to the corresponding receptors of target cells and for the death of target cells or stimulation of their functional activity. The second direction is formed by 2, 6, 7, and 9 lines and is associated with the development of nanoecotoxicology. This direction relates to developing methods for testing nanoparticles' damage to ecosystems and obtaining nanoparticles with new properties using green synthesis technologies. India, China, and partly European countries can become the flagships of this trend. The third direction is associated with lines 4 and 6 and reflects the need to develop new models of chronic nanotoxicity and new models of histological barriers for nanotoxicological testing. The fourth direction is formed by lines 5 and 8 and related to new technologies and nanoparticles synthesized by nanotechnology.

\section{Conclusions}

The prognosis for the development of nanotoxicology is often qualitative. For example, the goal of system nanotoxicology is to endeavor reproducibility and relevance to experimental nanosafety research and discovering nano-specific toxicity biomarkers and pathways. The toxicologists also 
believe that interconnections between human toxicology and the environment are vital and suggest that joint efforts could further benefit these two mutually related fields. The lack of standardized methods and materials consideration and incomplete statistics needs to be worked out to progress in this context. Addressing these issues will widen the scope for nanomaterials' reasonable use for nanobiotechnology-based pharmaceutical design to combat infection, neurological problems, and drug delivery (Singh et al., 2019).

One of the first forecasts for nanotoxicology development was the five grand challenges described by Maynard and colleagues in 2005 (Maynard et al., 2006). These requirements consisted of five main points: (1) equipment advancement over the next 5-15 years; (2) developing techniques for assessing the hazards of ENMs; (3) developing predictive models for hazardous effects; (4) developing methods for estimating long-term effects of ENMs; (5) facilitating methodologies for risk-focused research.

However, ten years later, two of the authors (Maynard and Aitken) assessed progress. It was concluded that appreciable progress had been made in advancing and funding essential programs to initiate health-related research regarding nanomaterials' safety. In contrast, little progress was made in developing instruments to monitor airborne or waterborne engineered nanomaterials or predictive methodologies for modeling applications (Maynard \& Aitken, 2016). Among the goals that the researchers set for nanotoxicology in 2018 (Warheit, 2018) were: (1) inter-laboratory studies for the validation of test methods and toxicity results; (2) development of new in vitro toxicity methodologies or cell culture techniques to simulate longer-term effects; (3) more useful definitions for nanomaterials are necessary; (4) focusing on biokinetics/toxicokinetics of nanoparticles at relevant human exposure levels.

In our study, we identified two trends associated with countries. The first trend is functionalizing systems with peptides to deliver nanoparticles to reduce the toxic load outside the target tissues (USA, China). The second one is nanoparticles' production with new properties using green synthesis technologies and research in nanoecotoxicology (India, China). Considering the effect of several citation centers demonstrated in Figure 3 (one of which is associated with the USA and the other with India and Asian countries), it is worthwhile to assume that both directions will develop in parallel in the future. Our results on the development of nanoecotoxicological studies coincide with the need to determine nanomaterials' environmental fate, predicted more than ten years ago by Alexis D. Ostrowski et al. (Ostrowski, Martin, Conti, Hurt, \& Harthorn, 2009).

Interestingly, the high level of nanotechnological research cannot ensure the intensive development of nanotoxicology. For example, significant and consistent growth in nanotechnology papers is noted in the three countries. Between 2000 and 2007, the average annual growth rate was $+31.43 \%$ in China, $+11.88 \%$ in Russia, and $+33.51 \%$ in India (Maynard \& Aitken, 2016). Despite Russia's high indicators, it does not appear among the leading countries of any rating. Further scientometric research should be aimed not only at studying the leading countries of nanotoxicology but also at assessing the mistakes of countries that could not realize nanotechnological research's potential. This may allow for a better assessment of the infrastructure features required for successful interdisciplinary research.

To summarizing, the formation of the nanotoxicology base as science was completed in 2010 2011. Subsequently, nanotoxicology development was based on improving its methodological base, analyzing the results of nanotechnological discoveries, and integrating into medical disciplines. Leading journals in which nanotoxicological research results have been published are ACS Nano, International Journal of Nanomedicine, Nanoscale, and Journal of Controlled Release.

Over the past decade, the USA, China, and Brazil have become centers for nanotoxicology development. However, most of the research in these countries is fundamental or directed towards medicine. At the same time, in countries such as India, Malaysia, Saudi Arabia, and Iran, research is more applied. They focus on ecotoxicity, agriculture, and nanosafety research. This leads to the fact that these two large clusters have no joint research and co-citation. There are also two methodological 
approaches to nanotoxicological research: intensive, typical for scientists from the USA, China, and Brazil, and extensive, typical for Asia's scientists.

More inter-laboratory and inter-institutions research can help overcome another issue connected with the difference in "pure" chemical, biological and medical approaches to nanotoxicology. The relatively strict division of journals into research areas, in our opinion, leads to the fact that some points are overlooked. At the same time, there is an apparent demand for multidisciplinary research, which is supported by such journals' popularity (e.g., ACS Nano). A more profound look into scientists' biography also proves that interdisciplinarity is the key factor for nanotoxicology advancement.

New trends in nanotoxicology after 2021 may be related to:

1. the development of nanoecotoxicology. Determination of methods for testing nanoparticles' damage to systems and obtaining nanoparticles with new properties using green synthesis technologies. India, China, and partly European countries can become the flagships of this trend;

2. more active inclusion of various peptides in the composition of nanoparticles, both to target nanoparticles to the corresponding receptors of target cells and for the death of target cells or stimulation of their functional activity. The USA and China may become the flagships of this trend;

3. the development of the methodological base of nanotoxicological testing.

\section{Competing Interests}

The authors have declared that no competing interest.

\section{References}

Anandhalli, G. (2018). Scientometric Analysis of Nanotechnology Literature From 2000-2016 As Reflected in. (May).

Churg, A., \& Brauer, M. (2000). Ambient atmospheric particles in the airways of human lungs. Ultrastructural Pathology, 24(6), 353-361. https://doi.org/10.1080/019131200750060014

de Castilhos Ghisi, N., Zuanazzi, N. R., Fabrin, T. M. C., \& Oliveira, E. C. (2020). Glyphosate and its toxicology: A scientometric review. Science of the Total Environment, 733, 139359. https://doi.org/10.1016/j.scitotenv.2020.139359

Department for Environment Food and Rural Affairs. (2008). UK Voluntary Reporting Scheme for engineered nanoscale materials. 12.

Donaldson, K., Stone, V., Tran, C. L., Kreyling, W., \& Borm, P. J. A. (2004). Nanotoxicology. Occupational and Environmental Medicine, 61(9), 727-728. https://doi.org/10.1136/oem.2004.013243

Fadeel, B. (2019). The Right Stuff: On the Future of Nanotoxicology. Frontiers in Toxicology, 1. https://doi.org/10.3389/ftox.2019.00001

Ferin, J., Oberdörster, G., Penney, D. P., Soderholm, S. C., Gelein, R., \& Piper, H. C. (1990). Increased pulmonary toxicity of ultrafine particles? I. Particle clearance, translocation, morphology. Journal of Aerosol Science, 21(3), 381-384. https://doi.org/10.1016/00218502(90)90064-5

Furxhi, I., Murphy, F., Mullins, M., \& Poland, C. A. (2019). Machine learning prediction of nanoparticle in vitro toxicity: A comparative study of classifiers and ensemble-classifiers using the Copeland Index. Toxicology Letters, 312, 157-166.

https://doi.org/10.1016/j.toxlet.2019.05.016

Hussain, S. M., Warheit, D. B., Ng, S. P., Comfort, K. K., Grabinski, C. M., \& Braydich-Stolle, L. K. (2015). At the crossroads of nanotoxicology in vitro: Past achievements and current challenges. Toxicological Sciences, 147(1), 5-16. https://doi.org/10.1093/toxsci/kfv106

Hutchins, B. I., Yuan, X., Anderson, J. M., \& Santangelo, G. M. (2016). Relative Citation Ratio 
(RCR): A New Metric That Uses Citation Rates to Measure Influence at the Article Level.

PLoS Biology, 14(9), e1002541. https://doi.org/10.1371/journal.pbio.1002541

Inshakova, E., \& Inshakov, O. (2017). World market for nanomaterials: Structure and trends.

MATEC Web of Conferences, 129. https://doi.org/10.1051/matecconf/201712902013

Karpagam, R. (2014). Global research output of nanobiotechnology research: A scientometrics

study. Current Science, 106(11), 1490-1499. https://doi.org/10.18520/cs/v106/111/1490-1499

Krabbenborg, L. (2013). DuPont and Environmental Defense Fund Co-Constructing a Risk

Framework for Nanoscale Materials: An Occasion to Reflect on Interaction Processes in a Joint

Inquiry. NanoEthics, 7(1), 45-54. https://doi.org/10.1007/s11569-013-0167-5

Lison, D., Vietti, G., \& van den Brule, S. (2014). Paracelsus in nanotoxicology. Particle and Fibre

Toxicology, 11(1). https://doi.org/10.1186/s12989-014-0035-7

Maynard, A. D., \& Aitken, R. J. (2016). "Safe handling of nanotechnology" ten years on. Nature

Nanotechnology, 11(12), 998-1000. https://doi.org/10.1038/nnano.2016.270

Maynard, A. D., Aitken, R. J., Butz, T., Colvin, V., Donaldson, K., Oberdörster, G., ... Warheit, D.

B. (2006). Safe handling of nanotechnology. Nature, 444(7117), 267-269.

https://doi.org/10.1038/444267a

Nano-Society. (2009). https://doi.org/10.1039/9781847559609

Navya, P. N., \& Daima, H. K. (2016). Rational engineering of physicochemical properties of nanomaterials for biomedical applications with nanotoxicological perspectives. Nano Convergence, 3(1). https://doi.org/10.1186/s40580-016-0064-z

Neagu, M., Piperigkou, Z., Karamanou, K., Engin, A. B., Docea, A. O., Constantin, C., ... Tsatsakis, A. (2017). Protein bio-corona: critical issue in immune nanotoxicology. Archives of Toxicology, 91(3), 1031-1048. https://doi.org/10.1007/s00204-016-1797-5

Oberdörster, G. (2010). Safety assessment for nanotechnology and nanomedicine: Concepts of nanotoxicology. Journal of Internal Medicine, 267(1), 89-105. https://doi.org/10.1111/j.13652796.2009.02187.x

Oberdörster, G., Ferin, J., Finkelstein, G., Wade, P., \& Corson, N. (1990). Increased pulmonary toxicity of ultrafine particles? II. Lung lavage studies. Journal of Aerosol Science, 21(3), 384 387. https://doi.org/10.1016/0021-8502(90)90065-6

Oberdörster, G, Ferin, J., Gelein, R., Soderholm, S. C., \& Finkelstein, J. (1992). Role of the alveolar macrophage in lung injury: studies with ultrafine particles. Environmental Health Perspectives, 97, 193-199. https://doi.org/10.1289/ehp.9297193

Oberdörster, Günter, Maynard, A., Donaldson, K., Castranova, V., Fitzpatrick, J., Ausman, K., ... Yang, H. (2005). Principles for characterizing the potential human health effects from exposure to nanomaterials: Elements of a screening strategy. Particle and Fibre Toxicology, 2(1), 8. https://doi.org/10.1186/1743-8977-2-8

Oberdörster, Günter, Oberdörster, E., \& Oberdörster, J. (2005). Nanotoxicology: An emerging discipline evolving from studies of ultrafine particles. Environmental Health Perspectives, 113(7), 823-839. https://doi.org/10.1289/ehp.7339

Ostrowski, A. D., Martin, T., Conti, J., Hurt, I., \& Harthorn, B. H. (2009). Nanotoxicology: Characterizing the scientific literature, 2000-2007. Journal of Nanoparticle Research, 11(2), 251-257. https://doi.org/10.1007/s11051-008-9579-5

Santamaria, A. (2012). Historical Overview of Nanotechnology and Nanotoxicology. In Methods in Molecular Biology (pp. 1-12). https://doi.org/10.1007/978-1-62703-002-1_1

Service, R. F. (2008). Report Faults U.S. Strategy for Nanotoxicology Research. Science, 322(5909), 1779.1-1779. https://doi.org/10.1126/science.322.5909.1779a

Singh, A. V., Laux, P., Luch, A., Sudrik, C., Wiehr, S., Wild, A. M., ... Sitti, M. (2019). Review of emerging concepts in nanotoxicology: opportunities and challenges for safer nanomaterial design. Toxicology Mechanisms and Methods, 29(5), 378-387. https://doi.org/10.1080/15376516.2019.1566425

Stark, W. J. (2011). Nanoparticles in biological systems. Angewandte Chemie - International Edition, 50(6), 1242-1258. https://doi.org/10.1002/anie.200906684

Surkis, A., \& Read, K. (2015). Research data management. Journal of the Medical Library Association, 103(3), 154-156. https://doi.org/10.3163/1536-5050.103.3.011

Takeda, Y., Mae, S., Kajikawa, Y., \& Matsushima, K. (2009). Nanobiotechnology as an emerging 
research domain from nanotechnology: A bibliometric approach. Scientometrics, 80(1), 23-38. https://doi.org/10.1007/s11192-007-1897-3

Trevisani, M., \& Tuzzi, A. (2018). Chronological corpora curve clustering: From scientific corpora construction to knowledge dynamics discovery through word life-cycles clustering. MethodsX, 5, 1576-1587. https://doi.org/10.1016/j.mex.2018.11.010

United States Government Accountability Office. (2010). United States government accountability office report on nanotechnology: Nanomaterials are widely used in commerce, but EPA faces challenges in regulating risk. International Journal of Occupational and Environmental Health, 16(4), 525-539. https://doi.org/10.1179/107735210799159932

van Eck, N. J., \& Waltman, L. (2010). Software survey: VOSviewer, a computer program for bibliometric mapping. Scientometrics, 84(2), 523-538. https://doi.org/10.1007/s11192-0090146-3

van Eck, N. J., Waltman, L., van Raan, A. F. J., Klautz, R. J. M., \& Peul, W. C. (2013). Citation Analysis May Severely Underestimate the Impact of Clinical Research as Compared to Basic Research. PLoS ONE, 8(4), e62395. https://doi.org/10.1371/journal.pone.0062395

Warheit, D. B. (2018). Hazard and risk assessment strategies for nanoparticle exposures: How far have we come in the past 10 years? F1000Research, 7, 376. https://doi.org/10.12688/f1000research.12691.1

Warheit, D. B., Webb, T. R., Reed, K. L., Frerichs, S., \& Sayes, C. M. (2007). Pulmonary toxicity study in rats with three forms of ultrafine-TiO2 particles: Differential responses related to surface properties. Toxicology, 230(1), 90-104. https://doi.org/10.1016/j.tox.2006.11.002

Wilson, F. J., Hiller, F. C., Wilson, J. D., \& Bone, R. C. (1985). Quantitative deposition of ultrafine stable particles in the human respiratory tract. Journal of Applied Physiology, 58(1), 223-229. https://doi.org/10.1152/jappl.1985.58.1.223

Yeung, A. W. K., Souto, E. B., Durazzo, A., Lucarini, M., Novellino, E., Tewari, D., ... Santini, A. (2020). Big impact of nanoparticles: analysis of the most cited nanopharmaceuticals and nanonutraceuticals research. Current Research in Biotechnology, 2, 53-63.

https://doi.org/10.1016/j.crbiot.2020.04.002 